\title{
Mathematical Modeling of the Transfer of Energy Forces from the Engine through Hydro Transmission and Hydro Differential to Executive Bodies
}

\author{
Farkhod Matmurodov ${ }^{*}$, Bozorboy Sobirov², Isomiddin Tulanov3, \\ Jakhongir Mirzaabdullayev ${ }^{4}$, Jamshid Khakimov ${ }^{4}$, Oybek Daminov ${ }^{4}$ \\ ${ }^{1}$ Turinsky the Polytechnical University in Tashkent, Tashkent, Uzbekistan \\ ${ }^{2}$ Urgench Branch of the Tashkent University of Information Technologies, Tashkent, Uzbekistan \\ ${ }^{3}$ Research Institute of Mechanization of Agriculture, Settlement of Gulbakhor, Uzbekistan \\ ${ }^{4}$ Tashkent State Technical University, Tashkent, Uzbekistan \\ Email: *matmurodov@yahoo.com
}

How to cite this paper: Matmurodov, F., Sobirov, B., Tulanov, I., Mirzaabdullayev, J., Khakimov, J. and Daminov, O. (2019) Mathematical Modeling of the Transfer of Energy Forces from the Engine through Hydro Transmission and Hydro Differential to Executive Bodies. World Journal of Mechanics, 9, 105-112.

https://doi.org/10.4236/wjm.2019.95008

Received: March 12, 2019

Accepted: May 7, 2019

Published: May 10, 2019

Copyright $\odot 2019$ by author(s) and Scientific Research Publishing Inc. This work is licensed under the Creative Commons Attribution International License (CC BY 4.0).

http://creativecommons.org/licenses/by/4.0/

\section{(c) (i) Open Access}

\begin{abstract}
Mathematically simulated energy transfers from the energy source to the chassis through hydro transmissions and hydro differential. The developed unified mathematical model of a dynamic system allows, at the design stage, of many branched drive mechanisms, including transmission hydraulic and hydraulic differential actuators, to explore dynamic processes and select rational parameters.
\end{abstract}

\section{Keywords}

Energy Forces, Dynamic System, Many-Branched Mechanism, Engine, Hydro Transmission, Hydro Differential

\section{Introduction}

The results of experimental studies of experimental structures indicate a high dynamic load during transient processes of moving off, shifting gears and locking hydraulic differentiation, as well as in steady-state motion modes of mobile machines, which limits the durability of the elements of power mechanisms [1]. This determines the need for in-depth research aimed at reducing dynamic loading.

At present, the available theoretical and experimental data for previously de- 
signed machines do not allow taking into account the potential properties of the designed machines, features of new design solutions, operating conditions, etc. Analytical methods for predicting durability and reliability based on the works of scientists and specialists were created for machines with low power at steady motion, for which the probability of moving at high speeds and high-loaded modes is not high. The mode of operation of many branched mechanisms of promising machines has not been scientifically studied.

Known mathematical models do not allow sufficiently taking into account the real design features, conditions and modes of motion control of machines, their interaction of parallel-sequentially installed driving mechanisms.

\section{Problem Definition}

One of the promising areas for improving the designs of wheeled vehicles and creating high-performance equipment is the use of volumetric hydraulic drives as a drive for the drive wheels of the undercarriage system. At present, industrial and agricultural mobile energy equipment (wheeled and tracked tractors) has been improved and has reached the level of mobile power facilities (MPF). MPF universal and unified tractor. It can simultaneously hang and fasten several different many operating machines in front, side and rear. In this case, there will be a lot of branching of the transmission of power from the engine to the actuators. In particular, energy is transmitted to the undercarriage, working actuators-to the drive shaft, a number of active working bodies. To describe these phenomena by mathematical expression is considered an important task.

Taking into account the influencing factors in the design of many branched mechanisms, including the flexibility of the working fluid and hydraulic drive elements, allows the design stage to provide a high technical level, reduce the amount of testing by increasing the reliability of calculations.

The creation of many branched mechanisms of a high technical level is hampered by the fact that the magnitudes of the influence of the flexibility of the working fluid, the elements of the hydraulic drive and the links of the mechanisms on its dynamic loading are insufficiently investigated. The influence of the flexibility of the working fluid and hydraulic drive elements on the optimal values of the parameters of the boom lifting mechanisms and the handle drive has not been taken into account.

The development of more accurate mathematical models of working processes of hydraulic mechanisms taking into account leaks in the hydraulic system, operation of safety systems, pliability of the working fluid and hydraulic drive elements makes it possible to fully and objectively determine the loads overcome by a many-branched mechanism during operation, and therefore evaluate the pressure state of the links, including number and in transient conditions.

The laboratory field tests of experimental tractors of the Research and Development Institute of Automobile and Tractor of Russia and the Institute of Agri- 
cultural Machinery (England) showed increased slipping of tractor wheels with hydro-transmission in comparison with mechanical transmission. At the same time, the Institute of Agricultural Machinery in Leipzig (Germany) and MTZ specialists note a reduction in slipping, which confirms the opinion of the influence of the type and parameters of the transmission, hydraulic machines and characteristics of working fluids on the traction properties of self-propelled machines.

From the side of Panasenko S.M. it was determined that the hydraulic drive of propulsion with high-torque hydraulic motors with kinematic perturbation or uneven rotation in the entire load range exceeds the skidding of the tractor with a mechanical transmission; Installing low-torque hydro motors helps reduce slippage when exposed to forced vibrations. The most rational volume hydraulic actuators of the tractor chassis are characterized by the use of high-speed hydraulic motors followed by a manual gearbox and torque reduction to the propulsion units. Such a scheme has higher dissipation properties, which exclude the sources of oscillations that tell the effect on the driving movement of the thrusters.

Usually, traditionally, after the transmission gearbox, the differential, semi-axle and front-wheel reducer is installed. All these mechanisms serve to reduce the power during transmission from the hydraulic motor to the wheel.

In the thesis [2], the hypothesis about the destruction of metal-ceramic disks of friction elements, the control system of hydromechanical transmission due to the occurrence of resonant modes, caused by high-frequency disturbances generated by the torque converter, is put forward and substantiated. Based on the results of the study, an improved method of friction elements is presented.

Energy transfer previously performed on all mathematical models is described in parts and in a vague form. The transmissions of generated power or power from the engine by a mathematical expression are not fully recorded in any scientific work. The creation of a multi-operational and multi-functional mobile power and super-power engine makes a single transfer model of the power from the engine through a lot of branched transmission mechanisms to the executive bodies written. Unity is a unified system of equations, which are written by the expression the generated energy of an engine in parallel-sequential order transmitting to the executive bodies. Basically, MPF uses mechanical, hydraulic and electric drive transmissions. In this paper, we model the mechanical and hydraulic drive mechanisms.

To write a single mathematical model, we accept the following assumptions: oscillation phenomena in all mechanisms and nodes are not taken into account; sustainability is not considered; not studied external perturbing all sorts of phenomena.

\section{Results and Discussion}

\subsection{Draw an Equivalent Design Scheme (Figure 1)}




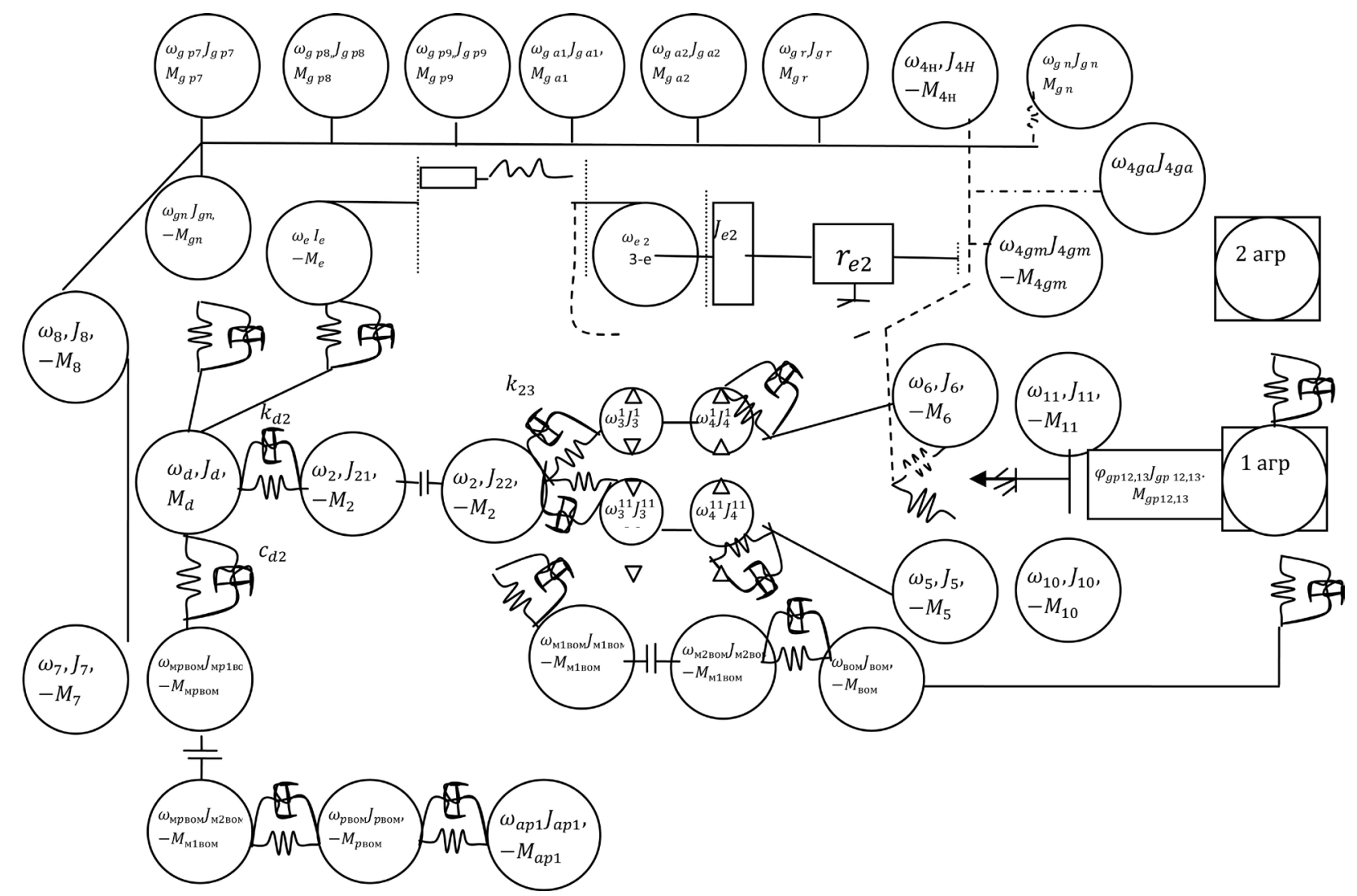

Figure 1. Design diagram of an equivalent integrated dynamic model of MPF with a technological module, rear and front units with hydraulic transmission and hydraulic differential.

\subsection{Describe the Transfer of Energy from the Engine to Branched Mechanisms Involving Hydraulic Transmission}

Equations describing the rotational motion of mechanisms from the engine

$$
\begin{gathered}
\left(J_{d}+J_{21}\right) \ddot{\varphi}_{d}+k_{d 2}\left(\dot{\varphi}_{d}-\dot{\varphi}_{2}\right)+c_{d 2}\left(\varphi_{d}+\varphi_{2}\right)=M_{d}-\frac{M_{2}}{i_{2}}, \varphi_{d}=\varphi_{2} \\
\left(J_{21}+J_{22}\right) \ddot{\varphi}_{2}+c_{2}\left(\varphi_{d}+\varphi_{2}\right)=-M_{2} \operatorname{sign}\left(\dot{\varphi}_{2}\right) i_{2}, \\
\left(J_{\text {мп вом }}+J_{\text {мп2вом }}\right) \ddot{\varphi}_{\text {мпвом }}+c_{\text {мпвом }}\left(\varphi_{d}+\varphi_{\text {мпвом }}\right)=-M_{\text {мпвом }} \operatorname{sign}\left(\dot{\varphi}_{\text {мпвом }}\right) x \\
x i_{\text {мпвом }},
\end{gathered}
$$

PTO n-clutch

$$
\begin{aligned}
J_{\text {вом }} \ddot{\varphi}_{\text {вом }}+k_{\text {вом }}\left(\dot{\varphi}_{2}-\dot{\varphi}_{\text {вом }}\right)+c_{\text {вом }}\left(\varphi_{2}+\varphi_{\text {вом }}\right)=-\frac{M_{\text {вом }} \operatorname{sign}\left(\dot{\varphi}_{\text {вом }}\right)}{i_{\text {вом }}}, \\
J_{\text {пвом }} \ddot{\varphi}_{\text {пвом }}+k_{\text {пвом }}\left(\dot{\varphi}_{\text {мпвом }}-\dot{\varphi}_{\text {пвом }}\right)+c_{\text {пвом }}\left(\varphi_{\text {мпвом }}+\varphi_{\text {пвом }}\right) \\
=-\frac{M_{\text {пвом }} \operatorname{sign}\left(\dot{\varphi}_{\text {пвом }}\right)}{i_{\text {пвом }}}
\end{aligned}
$$

n-PTO

Describes the transfer of energy through an extensive mechanism involving hydraulic transmission 


$$
\begin{aligned}
& J_{3}^{1} \ddot{\varphi}_{3}^{1}-k_{23}^{1}\left(\dot{\varphi}_{2}-\dot{\varphi}_{3}^{1}\right)-e_{23}^{1}\left(\varphi_{2}-\varphi_{3}^{1}\right)=-p_{1} R f \sin \gamma \sum_{k=0}^{n-1} \sin \left(\varphi_{3}^{1}-k \beta\right) / \eta_{H M}, \\
& J_{3}^{11} \ddot{\varphi}_{3}^{11}-k_{23}^{11}\left(\dot{\varphi}_{2}-\dot{\varphi}_{3}^{11}\right)-e_{23}^{11}\left(\varphi_{2}-\varphi_{3}^{11}\right)=-p_{2} R f \sin \gamma \sum_{k=0}^{n-1} \sin \left(\varphi_{3}^{11}-k \beta\right) / \eta_{H M}, \\
& J_{3}^{1} \ddot{\varphi}_{3}^{1} R f_{\text {дтэк }} \sin \gamma \sum_{k=0}^{n-1} \sin \left(\varphi_{3}^{1}+k \beta\right)=\varphi_{4}^{1} F \sum_{0}^{\theta} v_{\varphi}+p_{1} r+\dot{p}_{1} V_{1} / E, \\
& J_{3}^{11} \ddot{\varphi}_{3}^{11} R f_{\text {gтэк }} \sin \gamma \sum_{k=0}^{n-1} \sin \left(\varphi_{3}^{11}+k \beta\right)=\varphi_{4}^{11} F \sum_{0}^{\theta} v_{\varphi}+p_{2} r+\dot{p}_{2} V_{2} / E, \\
& J_{4}^{1} \ddot{\varphi}_{4}^{1}+k_{45}\left(\dot{\varphi}_{4}^{1}-\dot{\varphi}_{5}^{1}\right)+e_{45}\left(\varphi_{4}^{1}-\varphi_{5}^{1}\right)=p_{1} F \eta_{M M} \sum_{0}^{\theta} v_{\varphi}, \\
& J_{4}^{11} \ddot{\varphi}_{4}^{11}+k_{45}\left(\dot{\varphi}_{4}^{11}-\dot{\varphi}_{5}^{11}\right)+e_{45}\left(\varphi_{4}^{11}-\varphi_{5}^{11}\right)=p_{2} F \eta_{M M} \sum_{0}^{\theta} v_{\varphi}, \\
& J_{5}^{1} \ddot{\varphi}_{5}^{1}-k_{45}\left(\dot{\varphi}_{4}^{1}-\dot{\varphi}_{5}^{1}\right)+k_{56}\left(\dot{\varphi}_{5}^{1}-\dot{\varphi}_{6}\right)-e_{45}\left(\varphi_{4}^{1}-\varphi_{5}^{1}\right)+c_{56}\left(\varphi_{5}^{1}-\varphi_{6}\right)=-0.5 M_{\varphi} \\
& J_{5}^{1} \ddot{\varphi}_{5}^{11}-k_{45}\left(\dot{\varphi}_{4}^{11}-\dot{\varphi}_{5}^{11}\right)+k_{56}\left(\dot{\varphi}_{5}^{11}-\dot{\varphi}_{6}\right)-e_{45}\left(\varphi_{4}^{11}-\varphi_{5}^{11}\right)+c_{56}\left(\varphi_{5}^{11}-\varphi_{6}\right)=-0.5 M_{\varphi} \\
& k_{n} \dot{\varphi}_{3}^{1} \gamma-c_{n}\left(p_{1}-p_{2}\right)-c_{y} p_{1}-q_{g m} \dot{\varphi}_{4}-2 e_{23} \dot{p}_{1}=\left\{\begin{array}{l}
0, \text { при } p_{1}>p_{n k l} \\
r_{n k l} p_{1}-Q_{n n} \text { при } p_{1} \leq p_{n k l}
\end{array} ;\right. \\
& k_{n} \dot{\varphi}_{3}^{1} \gamma-c_{n}\left(p_{1}-p_{2}\right)-c_{y} p_{2}-q_{g m} \dot{\varphi}_{4}-2 e_{34} \dot{p}_{2}=\left\{\begin{array}{l}
0, \text { при } p_{2}>p_{n k l} \\
r_{n k l} p_{2}-Q_{n n} \text { при } p_{2} \leq p_{n k l}
\end{array} ;\right. \\
& M_{g m}=q_{g m}\left(p_{1}-p_{2}\right)-f_{\text {gтэк }} \dot{\varphi}_{4} \text {, } \\
& M_{n}=k_{n} \gamma\left(p_{1}-p_{2}\right)-f_{\text {пэ }} \dot{\varphi}_{3},
\end{aligned}
$$

where, $J_{3}^{1}, J_{4}^{1}, J_{3}^{11}, J_{4}^{11}, J_{5}^{1}, J_{5}^{11}$-are the reduced moments of inertia of the concentrated masses of the right and left pumps, right and left hydromators, and the leading right and left wheels; $\varphi_{2}, \varphi_{6}$-angular movement of the clutch and an active executive body; $\dot{\varphi}_{2}, \dot{\varphi}_{6}$-angular speed of the clutch and an active executive body; $k_{23}^{1}, k_{23}^{11}$-damping factor of the pump shaft, $e_{23}^{1}, e_{23}^{11}$-hydraulic compliance pressure pump parts; $R$-created efforts RJ; $\gamma$-angle of rotation of the pump control device; $r$-leakage ratio of RJ; $V_{1}, V_{2}$-volume in pressure and drain cavities; $E$-volume modulus of elasticity RJ; $k_{45}$-damping coefficient of hydraulic motor shaft; $e_{45}$-hydraulic compliance of the working part of the motor; $e_{23}, e_{34}$-hydraulic compliance of pressure and drain lines between the pump and the hydraulic unit; $k_{56}$-shaft damping ratio of the active executive body; $c_{56}$-circumferential rigidity of the shaft of the active executive body; $\varphi_{3}^{1}, \varphi_{4}^{1}$-angular displacement of the shaft in the right pump 3 and the right hydraulic motor $4 ; \varphi_{3}^{11}, \varphi_{4}^{11}$-the angular displacement of the shaft in the left pump 3 and in the left hydraulic motor $4 ; \varphi_{5}^{1}, \varphi_{5}^{11}$-are the angular displacements of the shaft of the link 5 from the side of the respective hydraulic motors; $F$-cross-sectional area; $\eta_{H M}, \eta_{M M}$-efficiency of the pump and hydraulic motor; $v_{\varphi}$-reduced speed of a high-speed hydraulic motor; $c_{n}, c_{y}$-hydraulic leakage and leakage rates; $p_{1}, p_{2}$-pressure in the pressure and discharge lines; $\dot{p}_{1}, \dot{p}_{2}$-time derivatives of pressure in the pressure and discharge lines; $p_{n k l}$ - pressure setting of the make-up valve; $r_{n k l}$-specific flow through the return pick valve; $k_{n}$-coefficient specific feed pump; $q_{g m}$-specific consumption of 
the hydraulic motor; $f_{\text {gтэк }}, f_{\text {пэк }}$-are the coefficients of the generalized equivalent damping of the pump and the hydraulic motor; $M_{g m}, M_{n}$-the moment created by the hydraulic motor and the pump; $M_{\varphi}$-the moment of engagement of thrusters with the ground.

The resulting components of the differential equations for the hydraulic pump NAR-53 in the form $\sum_{k=0}^{n-1} \sin (\varphi+k \beta)=0.5 \sin \varphi+2.83 \cos \varphi, \quad-20^{\circ} \leq \varphi \leq 20^{\circ}$, $\varphi_{3}^{1}, \varphi_{4}^{1}$-for angular displacement is written accordingly; hydromotor MG-265T $\sum_{0}^{\theta} v_{\varphi}=a+\mathrm{B} \varphi=18.55+3.044 \varphi$.

Moment of adhesion of propulsion with the ground is determined taking into account vibrodynamic effects of disturbing loads and variable wheel speed according to the formula [3]

$$
M_{\varphi}=\left[m q \varphi_{p}+(1-m)(c+q \operatorname{tg} \varphi)\right] F_{0} r_{k} \sqrt[\alpha]{\frac{\delta}{\delta_{\max }}} \sum_{i=1}^{n} \sqrt[\alpha]{i} \exp \left[-\alpha_{\tau}\left(\left|\ddot{\varphi}_{5}-\ddot{\varphi}_{c}\right| r_{k}\right)\right]
$$

here, $m$-saturation coefficient tire tread; $q$-normal tire pressure on the ground; $\varphi_{p}$-the walking angle; $c$-connectedness of the soil; $\varphi$-the angle of internal friction of the soil; $F_{0}$-contact area; $r_{k}$-the radius of the wheel; $\alpha$-an indicator depending on the type of soil; $\delta, \delta_{\max }$-shear characteristics; $\alpha_{\tau}-\mathrm{a}$ constant coefficient characterizing the physical and mechanical properties of soil; $\ddot{\varphi}_{c}$-acceleration of the load on the soil; $i$-quantitatively lugs that are engaged.

\subsection{Describes Energy Transfer in Hydro Differential}

According to the calculation scheme (4H, $4 \mathrm{gm}$ links) (Figure 1) and accepted assumptions, the mathematical model of the hydro differential action will be the system of equations [4]

$$
\left\{\begin{array}{l}
J_{4 H} \ddot{\varphi}_{4 H}=M_{4 H}-M_{p}-\beta_{4 H} \dot{\varphi}_{4 H} \\
J_{4 g m} \ddot{\varphi}_{4 g m}=M_{p}+M_{4 g m} \\
\left(V_{4 H} / 2 \pi\right) \dot{\varphi}_{4 H}-\left(V_{4 g m} / 2 \pi\right) \dot{\varphi}_{4 g m}=e \dot{p}+k_{0} p+f_{0} \dot{x}_{0} \\
p-p_{0}=0.5 k^{-2} \rho \dot{x}_{0}\left|\dot{x}_{0}\right| \\
f_{0} \dot{x}_{0} p_{0}^{2}=V_{3} p_{3} \dot{p}_{0}
\end{array}\right.
$$

$M_{p}=\left(V_{4 H} / 2 \pi\right) p-$ moment of pressure created RJ, $M_{4 g m}=M_{n}-M_{i}$, Initial conditions $\dot{\varphi}_{4 H}=150 c^{-1}, \dot{\varphi}_{4 H}=150 c^{-1}, p=0, p_{0}=p_{3}, \quad \dot{x}_{0}=0$.

Here, $J_{4 H}-$ moment of inertia reduced to the pump axis; $J_{4 g m}-$ moment of inertia of the hydraulic motor brought to the axis; $M_{4 H}$-torque axis of the pump; $M_{4 g m}$-torque of the motor axis; $M_{n}$-moment of resistance to the hydraulic motor axes; $M_{i}$-moment of the $i$-th link located in turn; $V_{4 H}, V_{4 g m}$ -volumes of the pump and hydraulic motor; $V_{3}, p_{3}, p_{0}$-volume, pre-charge pressure and pressure in the accumulator; $p$ - pressure in the pressure line; $\beta_{4 H}$ -damping coefficient of the pump; $\varphi_{4 H}, \varphi_{4 g m}$-angular displacements of the axis of the pump and the hydraulic motor; $k_{0}, e$-coefficient of volumetric losses in the hydraulic drive and the flexibility of the pressure line; $f_{0}, \dot{x}_{0}$ - cross-section and velocity of the RJ at the inlet of the hydro accumulator; $k, \rho$ 
- flow coefficient and the density of the RJ.

In the system of Equation (1), the first two equations reflect the rotation of the pump and the hydraulic motor, the third one-the flow rate of the fluid, the fourth one-the fluid flow in the throttle of the accumulator, the fifth-the change in pressure in the hydro accumulator.

In the absence of a hydro accumulator, the system of Equation (1) is simplified to three equations

$$
\left\{\begin{array}{l}
J_{4 H} \ddot{\varphi}_{4 H}=M_{4 H}-M_{p} \\
J_{4 g m} \ddot{\varphi}_{4 g m}=M_{p}+M_{4 g m} \\
\left(V_{4 H} / 2 \pi\right) \dot{\varphi}_{4 H}-\left(V_{4 g m} / 2 \pi\right) \dot{\varphi}_{4 g m}=e \dot{p}+k_{0} p
\end{array}\right.
$$

Initial conditions $\dot{\varphi}_{4 H}=150 c^{-1}, \varphi_{4 g m}=0, p=0$.

In relative coordinate $\theta=\varphi_{4 H}-5 \varphi_{4 g m}$, two equations of the system are distinguished (2)

$$
\left\{\begin{array}{l}
\ddot{\theta}+\left(V_{0} / 2 \pi\right) p=\varepsilon_{0} \\
-\left(V_{0} / 2 \pi\right) \dot{\theta}+e \dot{p}+k_{0} p=0
\end{array}\right.
$$

System of Equation (2) with $=0, \quad p_{1}=-p$ take the form

$$
\left\{\begin{array}{l}
J_{4 g m} \ddot{\varphi}_{4 g m}-\left(V_{4 g m} / 2 \pi\right) p=M_{4 g m} \\
e \dot{p}+k_{0} p+\left(V_{4 g m} / 2 \pi\right) \dot{\varphi}_{4 g m}=0
\end{array}\right.
$$

As a result of operational calculus, the angle, time and ways of braking are determined.

$$
\varphi_{T}=\dot{\varphi}_{0}^{2} / \varepsilon_{T} ; t_{T}=\varphi^{2} / \varepsilon_{T} ; \varepsilon_{T}=V_{4 g m} p_{0} .
$$

Load maxima on the motor axis

$$
p_{4 g m} \approx p_{0}+J_{4 g m} \dot{\varphi}_{0}^{2}\left(2 p_{0} e\right)^{-1} ; M_{4 g m} \approx\left(V_{4 g m} / 2 \pi\right) p_{4 g m} .
$$

For the functioning of the hydro differential with the connection with the drive wheels, we supplement the system of equations (1) and (2) corresponding to the transfer of power

$$
\begin{aligned}
& \left\{\begin{array}{l}
J_{4 H} \ddot{\varphi}_{4 H}=M_{4 H}-M_{p}-\beta_{4 H} \dot{\varphi}_{4 H} \\
J_{4 g m} \ddot{\varphi}_{4 g m}=M_{p}+M_{4 g m} \\
\left(V_{4 H} / 2 \pi\right) \dot{\varphi}_{4 H}-\left(V_{4 g m} / 2 \pi\right) \dot{\varphi}_{4 g m}=e \dot{p}+k_{0} p+f_{0} \dot{x}_{0} \\
p-p_{0}=0.5 k^{-2} \rho \dot{x}_{0}\left|\dot{x}_{0}\right| \\
f_{0} \dot{x}_{0} p_{0}^{2}=V_{3} p_{3} \dot{p}_{0} \\
J_{4 g m} \ddot{\varphi}_{4 g m}+k_{4 g m}\left(\dot{\varphi}_{4 g m}-\dot{\varphi}_{4}\right)+e_{4 g m}\left(\varphi_{4 g m}+\varphi_{4}\right)=p_{24} F_{4} \eta_{4 g m} \sum_{0}^{\theta} v_{\varphi 4} \\
J_{5} \ddot{\varphi}_{5}+k_{45}\left(\dot{\varphi}_{4}-\dot{\varphi}_{5}\right)+c_{45}\left(\varphi_{4}+\varphi_{5}\right)=-M_{5} \operatorname{sign}\left(\dot{\varphi}_{5}\right) i_{5}
\end{array}\right. \\
& \left\{\begin{array}{l}
J_{4 H} \ddot{\varphi}_{4 H}=M_{4 H}-M_{p} \\
J_{4 g m} \ddot{\varphi}_{4 g m}=M_{p}+M_{4 g m} \\
\left(V_{4 H} / 2 \pi\right) \dot{\varphi}_{4 H}-\left(V_{4 g m} / 2 \pi\right) \dot{\varphi}_{4 g m}=e \dot{p}+k_{0} p \\
J_{4 g m} \ddot{\varphi}_{4 g m}+k_{4 g m}\left(\dot{\varphi}_{4 g m}-\dot{\varphi}_{4}\right)+e_{4 g m}\left(\varphi_{4 g m}+\varphi_{4}\right)=p_{24} F_{4} \eta_{4 g m} \sum_{0}^{\theta} v_{\varphi 4} \\
J_{5} \ddot{\varphi}_{5}+k_{45}\left(\dot{\varphi}_{4}-\dot{\varphi}_{5}\right)+c_{45}\left(\varphi_{4}+\varphi_{5}\right)=-M_{5} \operatorname{sign}\left(\dot{\varphi}_{5}\right) i_{5}
\end{array}\right.
\end{aligned}
$$


here, $k_{4 g m}, \varphi_{4 g m}$-coefficient of damping and angular displacement and shafting between the hydraulic motor and link 4; $e_{4 g m}$-hydro hydraulics compliance; $p_{24}-\mathrm{RJ}$ pressure in the side of the link $4 ; F_{4}$ - sectional area; $\eta_{4 g m}-$ hydro motor efficiency; $v_{\varphi 4}$-reduced speed high-speed hydraulic motors of hydro differential.

The systems of Equations (5) and (6) are subject to the mechanisms under the condition $M_{\varphi 5}=0, M_{6} \neq 0$, and vice versa with $M_{6}=0, M_{\varphi 5} \neq 0$.

The system of Equation (5) reflects the hydromechanical network with a hydro accumulator and (6) without it.

\section{Conclusions}

A single mathematical model of the transfer of energy from the engine through a multi-branched transmission mechanism to the executive bodies is described by the expression of the transfer of energy from the joint work of mechanical and hydraulic actuators. The developed mathematical model of a dynamic system allows, at the design stage, of many branched drive mechanisms, including transmission hydraulic and hydraulic differential actuators, to explore dynamic processes and choose rational parameters of hydraulic drive compliance, time and damping coefficient, which are variable by selecting kinematic dynamic parameters, hydraulic motors working volume, the volume of the injection line and the reduced mass of inertia.

A unified mathematical model of the transfer of energy from the engine through many branched transmission mechanisms to the executive bodies take into account the hydraulic transmission and hydraulic differential.

\section{Conflicts of Interest}

The authors declare no conflicts of interest regarding the publication of this paper.

\section{References}

[1] Taratorkin, I.A. (2009) Development of Computational and Experimental Methods for Reducing Dynamic Loading and Increasing the Durability of Hydromechanical Transmissions of Transport Vehicles. Dissertation, Bauman Moscow State Technical University (MSTU), Russian Federation (RF), Kurgan, 1.

[2] Homichev, A.S. (2010) Improvement of the Design Calculation Methodology for Friction Elements of Hydromechanical Transmissions of Transport Vehicles. Dissertation, Izhevsk State Technical University (ISTU), Russian Federation (RF), Kurgan, 12.

[3] Panasenko, S.M. (1992) Influence of Kinematic and Dynamic Qualities of the Volumetric Hydraulic Drive of the Tractor Chassis on the Traction and Operational Performance. Dissertation, Kharkiv Automobile and Road Institute (KARI), Ukraine, Kharkov, 8-10.

[4] Spiridonov, S.V. (1993) Improving the Efficiency of Pruning with a Vertical Broaching Tree by Reducing the Dynamic Load. Dissertation, St. Petersburg Forest Technical Academy, Russian Federation (RF), St. Petersburg, 7-9. 